\title{
Erratum to: Regulation of Caveolin-1 and Junction Proteins by bFGF Contributes to the Integrity of Blood-Spinal Cord Barrier and Functional Recovery
}

\author{
Li-Bing $\mathrm{Ye}^{1} \cdot \mathrm{Xi}$-Chong $\mathrm{Yu}^{1} \cdot{ }^{1}$ Qing-Hai Xia ${ }^{1} \cdot$ Ying Yang ${ }^{1} \cdot \mathrm{Da}-\mathrm{Qing} \mathrm{Chen}^{2}$ • \\ Fenzan $\mathrm{Wu}^{3}$ - Xiao-Jie $\mathrm{Wei}^{3} \cdot \mathrm{Xie} \mathrm{Zhang}^{4} \cdot$ Bin-Bin Zheng ${ }^{5}$ Xiao-Bing $\mathrm{Fu}^{6}$.

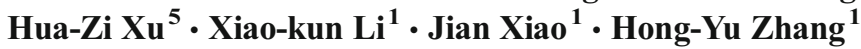

Published online: 1 December 2016

(C) The American Society for Experimental NeuroTherapeutics, Inc. 2016

\section{Erratum to: Neurotherapeutics (2016) 13:844-858}

DOI 10.1007/s13311-016-0437-3

In the original version of this article, figures 1 and 2 of the online Supplementary Material were corrupt due to a technical error. Below are the correct figure files.

The online version of the original article can be found at http://dx.doi. org/10.1007/s13311-016-0437-3.

Jian Xiao

xfxj2000@126.com

$\triangle$ Hong-Yu Zhang

hyzhang@wmu.edu.cn

1 School of Pharmaceutical Sciences, Key Laboratory of Biotechnology and Pharmaceutical Engineering, Wenzhou Medical University, Wenzhou, Zhejiang 325035, China

2 Emergency Department, The Second Affiliated Hospital, Wenzhou Medical University, Wenzhou, Zhejiang 325000, China

3 Department of Neurosurgery, Cixi People's Hospital, Ningbo, Zhejiang 315300, China

4 Ningbo Medical Treatment Center, Li Huili Hospital, Ningbo, Zhejiang 315000, China

5 Department of Orthopaedics, The Second Affiliated Hospital, Wenzhou Medical University, Wenzhou, Zhejiang 325000, China

6 Wound Healing and Cell Biology Laboratory, Institute of Basic Medical Science, Beijing, China 


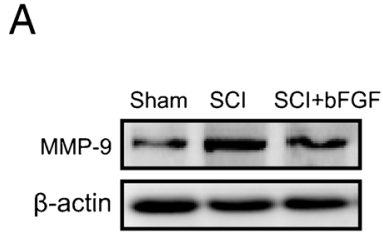

B
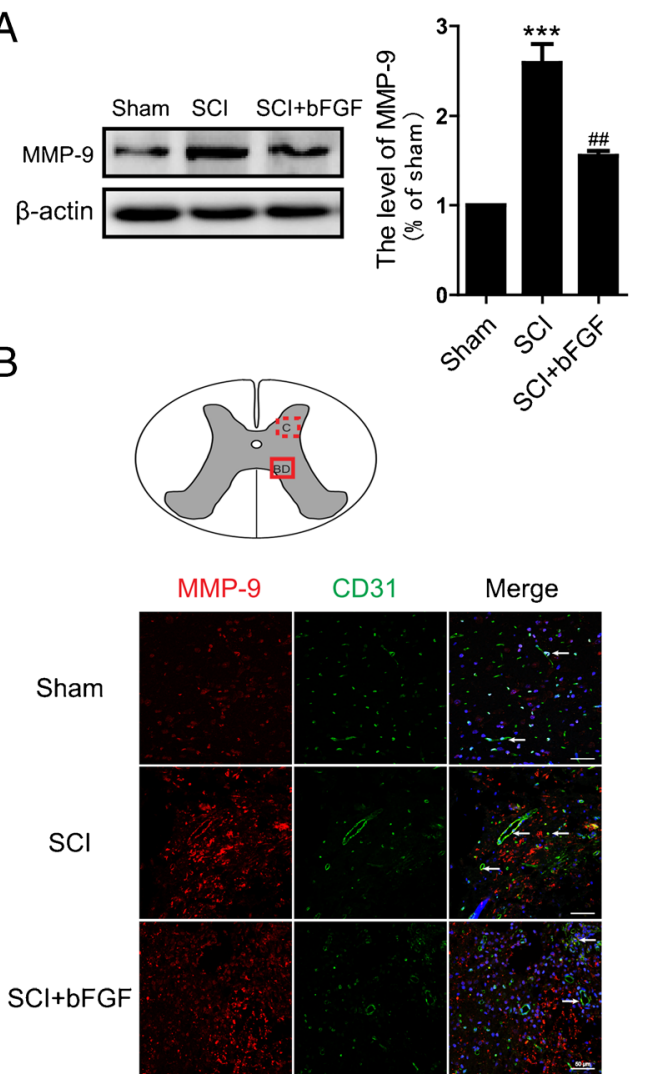

C

MMP-

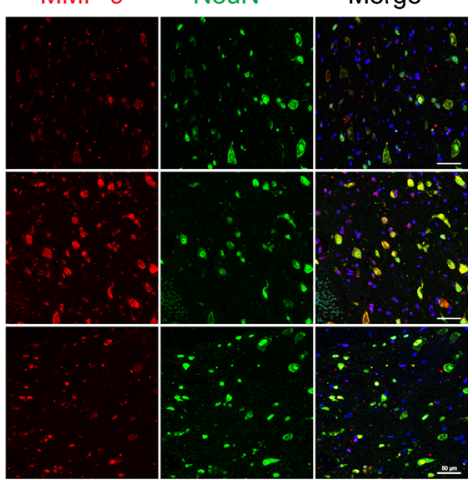

D

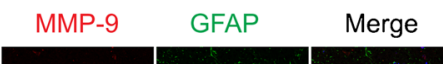

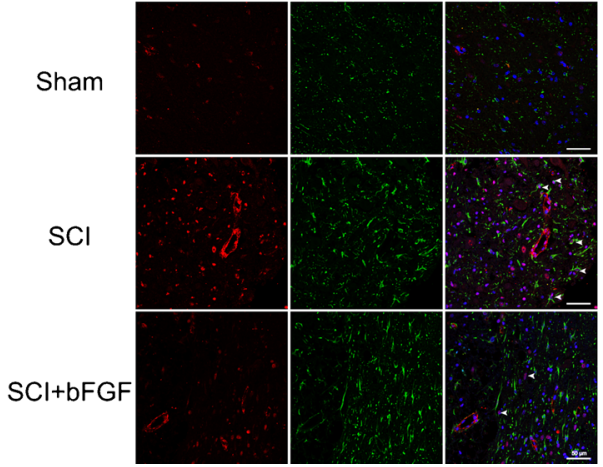

\section{Supplement}

A

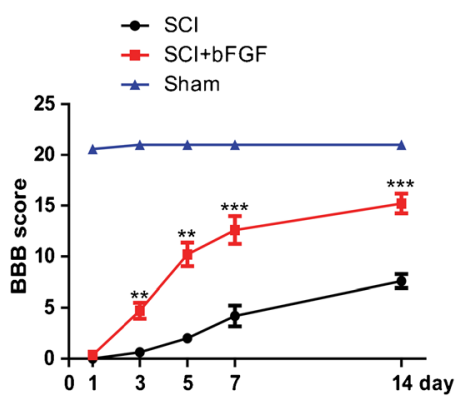

C

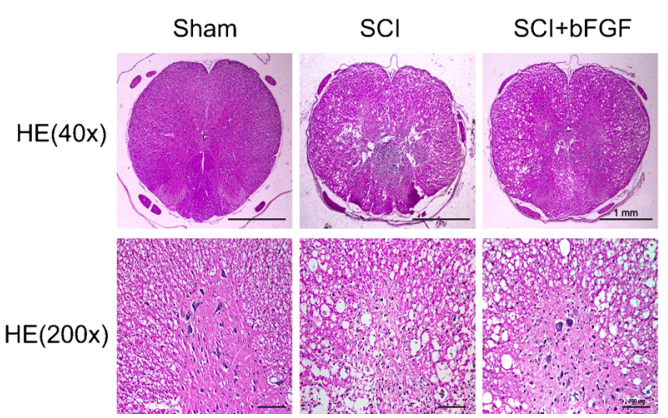

B

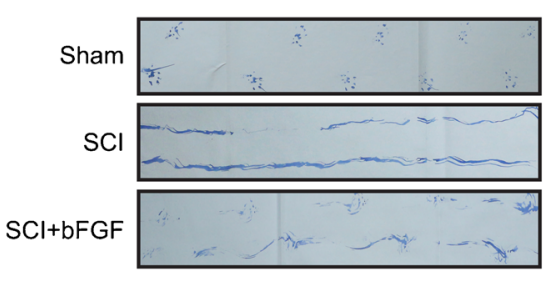

D

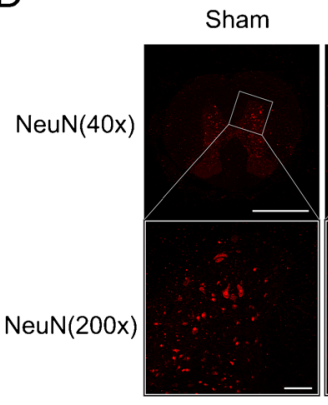

E

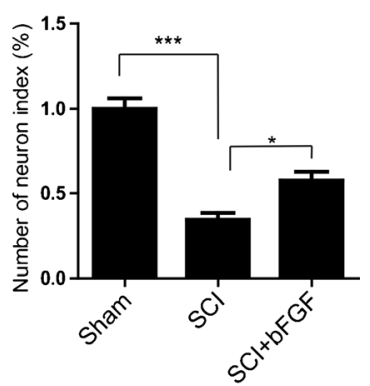

$\mathrm{SCl}$

$\mathrm{SCl}+\mathrm{bFGF}$

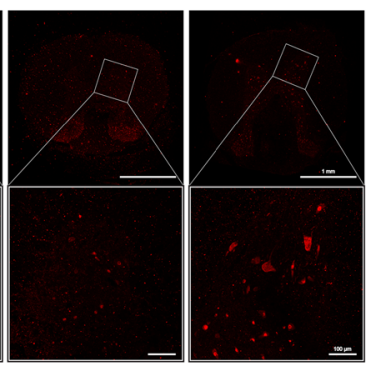

